\title{
Working together: reflections on building 'knowledge partnerships' between researchers, farmers and advisors
}

\author{
SEAN KENNY ${ }^{1}$ and CAROLYN KABORÉ ${ }^{2}$ \\ ${ }^{I}$ The University of Sydney, Camden, NSW, Australia, 2570 \\ ${ }^{2}$ The University of Melbourne, Parkville, Victoria, 3010 \\ seank@camden.usyd.edu.au
}

\begin{abstract}
In agricultural research, development and extension (RD\&E) the importance of building partnerships between technology collaborators (e.g. farmers, researchers, extension, industry) is widely accepted. The FutureDairy project has formalised relationships and interactions between farmers, researchers and advisors to 'co-develop' knowledge and technologies that address key industry challenges. Separate industry partnerships have been established to study opportunities in forages, feeding and labour saving innovations. Reflections on these partnerships, and their performance to date, suggests there may be benefit in knowledge partners having a better understanding of expectations for the partnership. Also highlighted is the way in which a technology codevelopment approach, though suited to developing guidelines for managing new technologies, may not be suited to systems questions. Issues that require multiple technologies and knowledge types to be addressed appear, from our experience, to require a different form of partnership than those used for developing new technologies. Without an understanding of these principles, RD\&E organisations may still fail to deliver on industry expectations even while they are encouraging greater industry participation.
\end{abstract}

Keywords: knowledge partnerships, co-development, feeding systems, complementary forage rotations, multidisciplinarity, partner farms, farming systems research project.

\section{Background to the FutureDairy Project}

With the decline in the terms of trade expected to continue on Australian dairy farms (ABARE, 2005), farmers are interested in determining the most appropriate future production systems. The availability and cost of land, water and labour along with the challenges associated with efficiently feeding dairy cows are seen as the key issues potentially limiting productivity growth of dairy farm systems (Garcia \& Fulkerson 2005). These form the focus of the FutureDairy project.

FutureDairy has three research modules - forages, feeding and innovations. The forages module aims to harvest over $40+\mathrm{t} \mathrm{DM} / \mathrm{ha} / \mathrm{yr}$ sustainably from a given area of land using a Complementary Forage Rotation (CFR) (Garcia et al. 2006). The feeding module is examining pathways to increasing milk solids production per hectare from dairy farms by $30-50 \%$. The innovations module is investigating a number of innovations that have the potential to improve farm efficiency, labour management and farming lifestyles, predominant amongst them being automatic milking systems (AMS).

\section{Background to Knowledge Partnerships}

The project is designed around 'knowledge partnerships' between researchers, both technical and social, extension agents and farmers (Nettle \& Kenny 2006). Various models are being employed in the Australian dairy industry (Paine 2005) with the concept of disciplines working together for rural innovation not being new (Langeveld \& Proost 2004). It is insufficient, however, to simply have commercial farmers 'linked' to research projects, trialling and demonstrating the same technologies as those under investigation at a central research site. Facilitated interactions between farmers, researchers and advisors are required, structured in such a way that relevant knowledge generated by each practice is shared and co-developed. Leeuwis (2000) suggests that this process of creating the conditions for the "right" interaction between technology collaborators is just as important as the technology itself. He also suggests a need for appropriate methodologies to encourage a form of interaction between researchers, farmers, extension and even society that enhances both the adaptation and use of technology and the performance of all actors in the knowledge system (farmers, researchers and advisors). Through partnering with commercial farms, FutureDairy has developed a number of sites where such methodologies and interactions can be applied and examined.

The project team - encompassing technical researchers, extension and social researchers - developed their roles around exploring with partner farmers the technical questions driving each module of research. A key role for project extension was to develop and support knowledge partnerships between researchers, partner farmers, their advisors and trusted peers, using a framework of management planning (Fig.1). The role of technical research in the partnership was to work closely with extension to develop reliable methods to assess, monitor and report technical and economic performance 
Figure 1 Management planning process used to facilitate interactions with partner farmers.

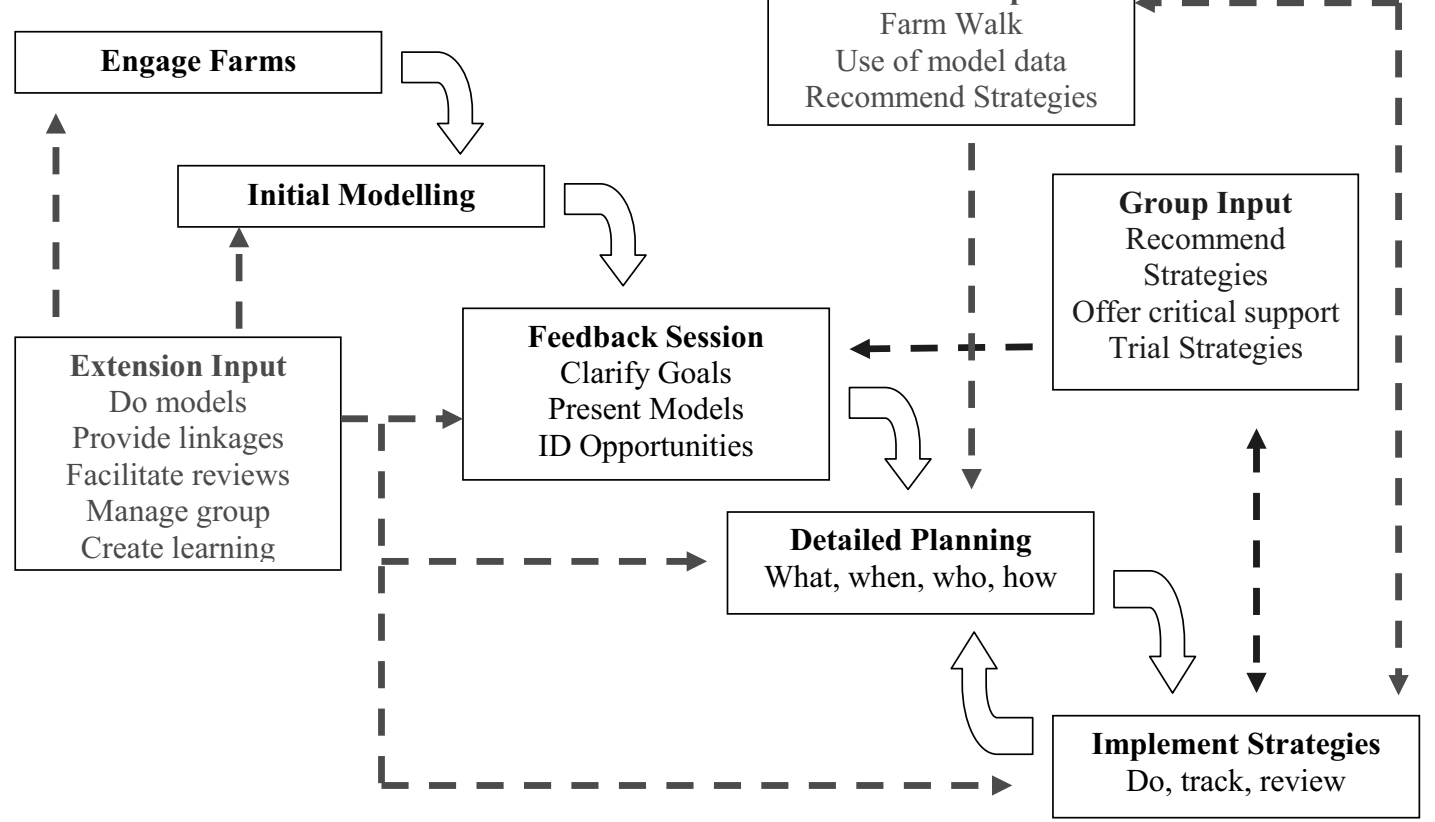

of each partner farm over time, and to contribute specialist technical expertise to the management planning process. In addition, technical research would respond to issues generated at the partner farm level by re-evaluating its research design and modifying where necessary. The primary role for social research was characterising farmer labour and lifestyle considerations around adaptation of specific technologies by partner farmers. Social research is also working with the project team to identify the benefits and constraints of multidisciplinary knowledge partnerships as an approach to developing technology.

For some participants, the main benefit from the project is expected to be the development and implementation of new technologies. For others there is a view that even if no 'mutually dependent' partnerships grow with regard to 'co-developing' specific technologies, the relationships from shared dialogue can still be mutually beneficial. Differentiation in expectations for knowledge partnerships has been an unexpected dynamic central to the critical analysis of knowledge partnerships as discussed below.

\section{Experience in the Complementary Forage Rotation (CFR) Module Partnership}

As a result of the knowledge partnership, the project was able to either achieve or make significant progress on all the objectives set, namely: 1) describe the approach taken by farmers to incorporate a CFR into their farm operation; 2) help develop a better understanding and articulation of the aspects of this approach that may be useful to other farmers; 3) apply the knowledge being generated from the forage module within FutureDairy on a commercial farm; 4) provide a 'reality check' for research to ensure that their experimental designs are addressing questions posed by dairy farmers, and overall; 5) evaluate the whole of farm implications of a complementary forage system aiming to sustainably utilise $40 \mathrm{t} \mathrm{DM} / \mathrm{ha} / \mathrm{yr}$ through a CFR.

Research at the forage partner farm sites has led to a greater understanding of the effect of scale on implementation of CFR on commercial farms. Grazing a commercial scale area of brassica (one of three crops in the CFR) is challenging compared with grazing 1 ha with a small number of cows at the research site. The planning, time and labour required to manage controlled grazing (e.g. 40 to 60 minutes) of allocated areas of brassica with large numbers of animals creates a burden which may significantly constrain success of the CFR on commercial farms. As a result, future forage research at the research site and on partner farms will look at different grazing strategies for brassica crops.

In addition, due to the grazing requirement for the brassica crop, the CFR was positioned close to the dairy on each partner farm for easy access. As a result, valuable areas of irrigated pasture were taken out of production throughout the maize cycle and farmers had to manage a reduction in feed supply. A fully grazed CFR would overcome this constraint, or alternatively, a fully 
harvested CFR positioned on areas of the farm inaccessible for grazing with the milking herd. Forage research will be expanded to compare performance of these new systems. In addition, a two-crop CFR, will be explored in the coming years in an attempt to overcome the practical challenges of growing three crops in one year - a significant practical constraint in some dairy regions due to climate.

The knowledge partnership has therefore enabled the farmer's knowledge and experience to contribute to the research directly and not be limited to just 'testing' a technology on farm. There was also an opportunity for the project team to participate in on-farm planning and learn more about the perspective of the farmer. Perhaps most importantly, with this interaction came recognition of the need for new technical options to be examined for the CFR research. This was a valuable example of 'codevelopment' in the FutureDairy project and of the benefits possible from effective knowledge partnerships.

\section{Experience in the Feeding Module Partnership}

When farmers seek improvements in milk production per hectare they are faced with a myriad of managerial challenges that go well beyond the use of any one technology. Questions around the physical (cow type, forage base, dairy), economic (capital structure, equity, cash flow, stage of business development) and social (worldview, family status, labour structure) resources of the farm have to be addressed. In a research environment studying increased production, the challenge is to create a controlled environment where a select number of variables can be explored in detail. The limitation of this approach to technical research relates to the time taken to explore all the variables associated with understanding 'systems' issues, whilst farmers have to manage these same variables every day. Simplifying questions about farming systems, to provide verifiable 'facts' around the 'keys' to managing improvements in milk production, will generally fail to meet the expectations of farmers dealing with complex systems as a part of their everyday experience. In this module, a more systematic issue was being examined. This is vastly different from research that is narrow in focus, exploring a specific element of farming activity for which a number of verifiable 'facts' can be generated quickly and then further developed 'in the field' with farmers (such as growing and managing CFR).

With regard to facilitating the partnership around the feeding module, our experiences were different to those of the forages module. Expectations for co-development of knowledge around feeding and farm productivity pathways were clearly a systems focus, rather than a technology focus. Despite this, the approach and the anticipated outcomes for the feeding module were similar to those for the forages module. Such outcomes were that research and extension would learn from farmers and farmers would learn about the technical research which would have practical benefits for farm management. However, in early meetings it became evident that farmers focussed primarily on the benefits from linking with research and were confused and frustrated by the idea that researchers were also interested to learn from them (Kenny \& Nettle 2006). This group of farmers had expectations for an approach where researchers acted as consultants by diagnosing problems and providing solutions.

\section{"We understood it was almost hands-on and more} technical support coming through"...." Most farmers when they see you coming in from outside, say you've got the 'magic medicine',... but that wasn't part of the project and probably that was the false illusion we had of it at the start..." (Partner farmer).

It is interesting to explore this mismatch between project team and farmer expectations. At one level it may be a function of not adequately defining expectations at the beginning. Three meetings were held between the farmer, their support group and local extension to discuss the objectives of the project and the role of the partner farm. Along with this, an extra two meetings were held with the partner farmer alone to clarify exactly what was expected of him and what the likely outcomes would be. The primary message being communicated was that the project team would explore the whole farm system implications of improving milk production per hectare by $30-50 \%$ through supporting the farmer to achieve this whilst examining, through technical and social research, the pathway pursued. It was the view of both local and project extension that this was adequate and the response from the farmers initially supported this view.

However, as discussed above, this was not actually the case. A key activity missing from this round of meetings was a rigorous process to clarify farmer expectations. It was assumed that the verbal agreement from the farmers as to the objectives of the partnership was sufficient. What subsequently came to light was a clear difference between what the project team thought was communicated and what was actually interpreted by the farmers. It is beyond the scope of this paper to explore all the potential reasons for this, apart from the fact that farmers were assuming their 'normal' role as participants in research and development programs, namely passive recipients and end users of the 'magic medicine' of research.

Needless to say, the goals of the knowledge partnership had to be explained and re-explored several times before there was a general agreement amongst the farmer support group as to the objectives of the 
partnership. Such an agreement was along the lines of the project teams expectations, with the concepts of the partnership eventually agreed on in principle, allowing the management planning process to commence. Planning meetings with the farmer were attended by regional extension, project technical researchers and the projects extension leader. In the following months, all seemed to be going to plan, group meetings were held and project extension, technical and social research participated in some of the meetings. However, both at the farm and extension levels, questions were raised about the feeding research within the project and a perceived lack of connection with what was being explored through the knowledge partnerships on the feeding partner farms.

While the FutureDairy feeding research was supported by extension, under the knowledge partnership arrangement, extension could not deliver anything directly from the research to the farm, and vice versa. Over time, the extension leader became increasingly aware that regional extension people were struggling with their role in the knowledge partnership, and had began questioning their role in the project:

"The research side is incredibly clear. It is that increase in [milk] production [per hectare], 40 tonnes [of dry matter per hectare], innovation... But as you move then to the partner farm and the relationship back, it is less clear ... and then when we go to [the] support people... we really need to start questioning, what's their role?" (Regional extension support person)

In addition, extension at both the project and regional level continued to feel that farmers potentially saw them as not delivering on expectations. This was particularly an issue with the support group. The partner farmer explained that, from their perspective, nothing seemed to be "happening":

I think it hasn't engaged the group as much as it could have. I still think there is huge potential... but

I don't know the answers and how to engage them... (Partner farmer)

At the same time, the regular meetings and telephone calls with regional extension and the one-on-one advice about farm management was seen as the most beneficial element of the partnership for the farmer. The partner farmer sensed he was in consultancy relationship with his local advisor, and questioned the nature of the link with the rest of the FutureDairy project.

"... is it... almost like a consultant working with a farmer... all along? Has he gained all that if he has been working with the same bloke for three or four years, would he have gained what you guys are trying to learn?" (Partner farmer)

Over time this has led a questioning of the role of partner farms in the feeding module of research. Some of the project team believe that 'co-development' wasn't happening on the feeding farms because no particular technology or approach was being tested (or replicated) as on the research farm. Also, there seemed to be no 'mutual dependency' between the 'feeding' research and the 'feeding' partner farms; the same outcomes could be achieved at both sites independently from one another. So why the need for a partnership?

The question this has raised for the project team is: why has the concept of farmers, researchers and extensionists working together around the question of increasing milk production created so much uncertainty and conflict whereas the forages partnerships have worked well?

\section{Reflections on Knowledge Partnerships}

At this stage in the Future Dairy project the feeding module has had conflicting expectations between researchers, extensionists and farmers. These same conflicts have not occurred in the CFR module and are unlikely to occur with it in the future. Central to the success of the forages knowledge partnership is the CFR technology. This technology has provided a focus for interactions and an entry point into the farming system for FutureDairy researchers and extension staff. Through the CFR there is an opportunity for researchers, farmers and extension to co-develop the principles and practices required to make a CFR work on farm. In contrast there is no particular technology to co-develop within the feeding module. The feeding research is designed to quantify a specific question around the profitability of two pathways to improved production per hectare. To do this, existing knowledge around grazing and feeding management is being applied in such a way that the most profitable approach to improving production per hectare can be explored. Such knowledge is already widely accessible and as such there is nothing 'new' for members of the knowledge partnership to work together on.

This case highlights two important insights which should inform future application of the knowledge partnership concept. First, is the importance of articulating expectations for knowledge partnerships relative to the research question. For our feeding partner farms, there was an expectation amongst many partnership members for 'co-development' outcomes similar to those from the forages research. What wasn't articulated clearly was the expectation that interactions between farmers, researchers and advisors within the knowledge partnership also offered significant gains. Leeuwis' (2000) statement, that the interactions between technology collaborators are as important as technology itself, did not adequately influence the approach taken with partner farms in the feeding module.

In light of this, the second insight relates to the approach 
taken to implementing knowledge partnerships. It is clear that the 'co-development' approach to knowledge partnership has worked well for the forages module, and central to this success has been the CFR technology. However this method was not as successful in forging effective partnerships around the system oriented question of profitably improving milk production per hectare. For a majority of participants in our knowledge partnerships, the partnership has been seen as a means to an end, not an end in itself. Without a specific technology to work on together, the partnership has had no 'end', hence questions of purpose and relevance have arisen. This is not to negate the value of having researchers, farmers and extension work together to solve problems. It simply highlights that from a knowledge partnership point of view, working together around genuine systems questions may require a different approach than if an element of this system is the key issue under analysis. Partnerships may need to take on a different nature, utilising technical research and researchers in different ways to those where a specific technology is being further developed with commercial farmers.

\section{Conclusion}

FutureDairy knowledge partnerships have been designed to achieve co-development of knowledge around the key areas of feeding, forages and innovations. Through practice, it has emerged that understanding and expectations around the feeding farm partnerships are not uniform among participants. At the project level the underlying philosophies about partnerships and the accepted forms of co-development are debated; at the partner farm level, lack of anticipated technical directives has led to frustration; and at the extension and advisory level, participants struggle to understand what they are expected to deliver and have difficulty identifying the benefits of the model. All of these insights have led to some key reflections on the facilitation of knowledge partnerships in practice:

- There is a clear need to clarify expectations of prospective 'knowledge partners' relative to the research question being explored prior to the establishment of knowledge partnerships;

- It would seem that systems oriented questions will struggle to fit the 'co-development' view of knowledge partnership. A different form of partnership is needed that can provide:
- A focus on learning outcomes rather than technological outcomes alone;

- A clarity of purpose for the partnership particularly when tackling difficult issues that will consistently challenge the integrity of the partnership;

- Facilitated interactions and processes that build the capacity of knowledge partners to better resolve system limitations to improved farm performance. This is in contrast to an approach that studies the interactions alone.

\section{REFERENCES}

ABARE 2005. Production systems, productivity and profit. Australian Bureau of Agricultural Resource Economics.

Garcia S.C.; Fulkerson W.J.; Nettle R.A.; Kenny S.N. 2006. FutureDairy: a national, multidisciplinary project to assist dairy farmers manage future challenges Early learnings. In: Proceedings of the National Dairy Science symposium, Mt Gambier, Sth Australia.

Garcia S.C.; Fulkerson W.J. 2005. Opportunities for future Australian dairy systems: a review. Australian Journal of Experimental Agriculture 45: 1041-1055.

Kenny S.N.; Nettle R.A. 2006. Knowledge partnerships 2: extension juggling multidisciplinarity in the fieldearly learnings from the FutureDairy project. In: Proceedings of the 2006 APEN International Conference, Beechworth, Victoria.

Langeveld, H.; Proost, J. 2004. Participative Learning for the Future; using interactive farmer-research networks in the development of new plant production systems in the Netherlands. Farming and Rural Systems Research and Extension. pp 537-545 In: Proceedings of the 6th IFSA European Symposium. Volume 2, Vila Real, Portugal.

Leeuwis. C. 2000 Learning to be sustainable. Does the Dutch agrarian knowledge market fail? The Journal of Agricultural Education and Extension 7(2): 79-92.

Nettle R.A.; Kenny S.N. 2006. Knowledge Partnerships 1: What can knowledge partnerships offer agricultural industries? - early learnings from the FutureDairy project. In: Proceedings of the 2006 APEN International Conference, Beechworth, Victoria.

Paine, M.S. 2005. The place of farms in systems R\&D and extension. Discussion Paper. National Dairy Farm Systems extension workshop 8-9 March, Melbourne, 2005. 